failure $^{3}$ and aiding in surgical planning. Further, this case illustrates that the spatial and temporal resolution of CT imaging has improved such that the diagnosis of coronary artery disease as well as of complex intracardiac pathology is now possible, even in the presence of severe tachyarrhythmia. In select cases, real-time dynamic CT imaging may eventually replace echocardiography and angiography and allow evaluation with a single test.

\section{References}

1. Nishimura RA, Schaff HV, Shub C, Gersh BJ, Edwards WD, Tajik AJ. Papillary muscle rupture complicating acute myocardial infarction: analysis of 17 patients. Am J Cardiol. 1983;51:373-7.
2. Devineni R, McKenzie FN. Acute mitral insufficiency resulting from blun chest trauma. J Thorac Cardiovasc Surg. 1983;85:797-8.

3. Hendel RC, Patel MR, Kramer CM, Poon M, Hendel RC, Carr JC. ACCF/ACR/ SCCT/SCMR/ASNC/NASCI/SCAI/SIR 2006 appropriateness criteria for cardiac computed tomography and cardiac magnetic resonance imaging: a report of the American College of Cardiology Foundation Quality Strategic Directions Committee Appropriateness Criteria Working Group, American College of Radiology, Society of Cardiovascular Computed Tomography, Society for Cardiovascular Magnetic Resonance, American Society of Nuclear Cardiology, North American Society for Cardiac Imaging, Society for Cardiovascular Angiography and Interventions, and Society of Interventional Radiology. J Am Coll Cardiol. 2006;48: 1475-97.

4. Kim TH, Seung KB, Kim PJ, Baek SH, Chang KY, Shin WS, et al. Images in cardiovascular medicine. Anterolateral papillary muscle rupture complicated by the obstruction of a single diagonal branch. Circulation. 2005;112:e269-70.

5. Waters BL. Clinical and pathologic factors contributing to acute papillary muscle ischemia. Arch Pathol Lab Med. 1990;114:601-4.

\title{
False aneurysm after transapical aortic valve implantation
}

Nawwar Al-Attar, FRCS, FETCS, PhD, Richard Raffoul, MD, Dominique Himbert, MD, Eric Brochet, MD, Alec Vahanian, MD, FRCP, and Patrick Nataf, MD, Paris, France

Video clip is available online.

\section{CLINICAL SUMMARY}

An 81-year-old man with severe aortic valve stenosis had repeated bouts of acute pulmonary edema (New York Heart Association class III). He had known triple-vessel coronary artery disease, chronic bronchitis, peripheral artery disease, and chronic atrial fibrillation. Echocardiography showed a mean gradient across a tricuspid aortic valve of $45 \mathrm{~mm}$ $\mathrm{Hg}$ with a calculated surface area of $0.38 \mathrm{~cm}^{2}$. It also showed functional mitral regurgitation (grade $2 / 4$ ) with heavy calcifications of the mitral annulus and severe pulmonary hypertension $(80 \mathrm{~mm} \mathrm{Hg})$. The left ventricular ejection fraction (LVEF) was calculated to be $15 \%$. Dobutamine stress echocardiography demonstrated a mild improvement of the LVEF and some contractile reserve. The EuroSCORE and Society of Thoracic Surgeons (STS) preoperative scores were $31 \%$ and $20 \%$, respectively. Conventional surgery was considered too risky and the patient was referred for

\footnotetext{
From the Bichat Hospital, Paris, France.

Received for publication June 18, 2008; accepted for publication July 6, 2008

Address for reprints: Nawwar Al-Attar, FRCS, FETCS, PhD, Department of Cardiac

Surgery, Hopital Bichat, 46 rue Henri Huchard, 75018 Paris, France (E-mail:

nalattar@gmail.com).

J Thorac Cardiovasc Surg 2009;137:e21-2

$0022-5223 / \$ 36.00$

Copyright (c) 2009 by The American Association for Thoracic Surgery

doi:10.1016/j.jtcvs.2008.07.018
}

transcatheter aortic valve implantation (TAVI). During his workup, he had low cardiac output and acute renal failure necessitating emergency aortic balloon valvuloplasty as a bailout procedure. After diminution of the gradient to $27 \mathrm{~mm} \mathrm{Hg}$ and improvement of renal function, TAVI was successfully performed through a left anterolateral thoracotomy via the transapical route with a balloon-expandable transcatheter xenograft (Edwards SAPIEN THV, Edwards Lifesciences, Irvine, Calif) $26 \mathrm{~mm}$ in diameter. An intra-aortic balloon pump was inserted after the procedure. Excess of anticoagulation contributed to a pericardial effusion of $600 \mathrm{~mL}$ that was drained 2 weeks after the operation. Echocardiography at 1 month demonstrated a functional prosthesis, negligible posterior leak $(<1 / 4)$, a mean gradient of $9 \mathrm{~mm} \mathrm{Hg}$, LVEF of $25 \%$, and pulmonary artery pressure of $35 \mathrm{~mm} \mathrm{Hg}$.

Three months after the procedure, the patient returned with a sudden-onset pulsating mass of $4 \mathrm{~cm}$ in diameter on the lateral aspect of the thoracotomy scar but was otherwise completely free of symptoms. Computed tomographic scan of the thorax showed a false aneurysm of the left ventricle of $50 \times 22$ $\mathrm{mm}$ dimension communicating with a pouch in the thoracic wall of $28 \times 27 \mathrm{~mm}$ diameter with enhancement at injection of contrast material (Figure 1). Echocardiography confirmed the presence of a left ventricular apical aneurysm with an LVEF of $34 \%$, good left ventricular kinetics, and a functional bioprosthesis; Doppler study confirmed flow within the aneurysmal sac (Figure 2 and Video E1). Surgical closure of the fistula was performed through sternotomy and cardiopulmonary bypass (CPB) accompanied by bypass grafting of the left anterior descending artery by the left internal thoracic artery. The patient made an uneventful recovery. 

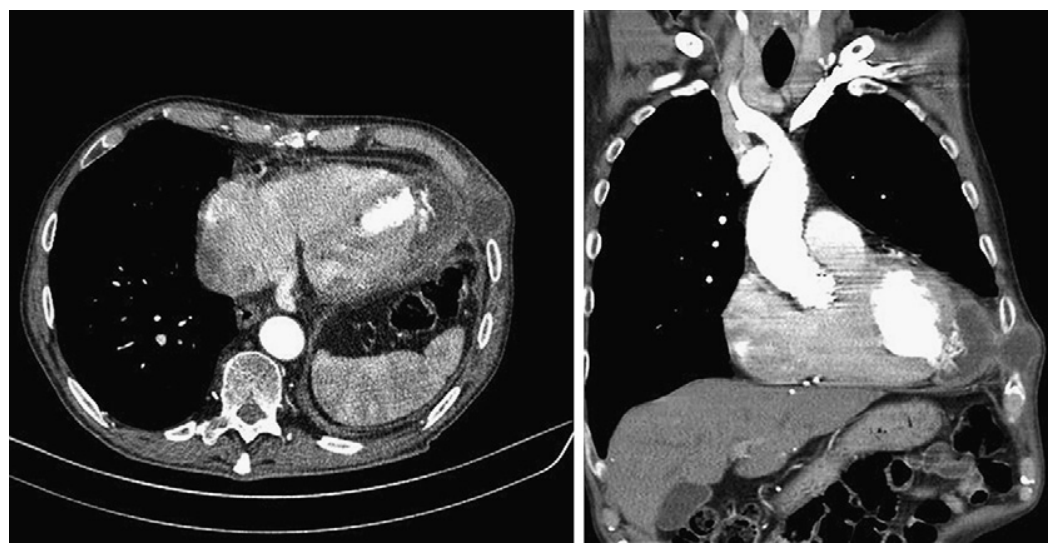

FIGURE 1. Computed tomographic scan (coronal and transverse sections).

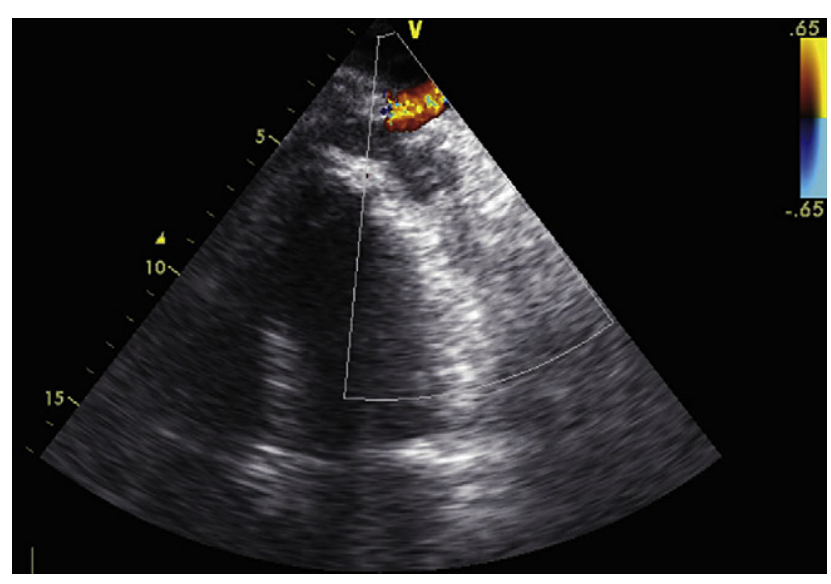

FIGURE 2. Echocardiography with Doppler study showing flow within the aneurysmal sac.

\section{DISCUSSION}

TAVI offers a novel therapeutic approach in high-risk patients with severe symptomatic aortic stenosis. ${ }^{1}$ Despite a successful procedural outcome and discharge from hospital, a false aneurysm developed at the site of apical puncture. The localization to the apex is unusual, and this is the first time it has been described after TAVI. Ventricular pseudoaneurysms have been reported after transmural myocardial infarction, chest trauma, infective endocarditis, tumors, and cardiac surgery. ${ }^{2}$ Surgical management is indicated to prevent rupture and can be achieved by direct suture closure with $\mathrm{CPB} .{ }^{3}$ The improvement of the patient's clinical status after TAVI allowed subsequent CPB for the repair of the aneurysm and bypass grafting of the left anterior descending artery. Even though further surgery was not planned for this patient, TAVI acted as a bridge procedure.

\section{References}

1. Vahanian A, Alfieri O, Al-Attar N, Antunes M, Bax J, Cormier B, et al. European Association of Cardio-Thoracic Surgery; European Society of Cardiology; European Association of Percutaneous Cardiovascular Interventions. Transcatheter valve implantation for patients with aortic stenosis: a position statement from the European Association of Cardio-Thoracic Surgery (EACTS) and the European Society of Cardiology (ESC), in collaboration with the European Association of Percutaneous Cardiovascular Interventions (EAPCI). Eur Heart J. 2008;29: 1463-70.

2. Bizzarri F, Rose D, Frati G, Muzzi L. Left ventricular postoperative false aneurysm following apical venting. J Cardiothorac Surg. 2006;1:41.

3. Rittenhouse EA, Sauvage LR, Mansfield PB, Smith JC, Davis CC, Hall DG. False aneurysm of the left ventricle. Report of four cases and review of surgical management. Ann Surg. 1979;189:409-15. 